\section{Pferdeenzephalitis-Viren, Ostamerikanische (EEEV)}

\section{W. Stöcker}

Euroimmun Medizinische Labordiagnostika AG, Lübeck, Deutschland

Englischer Begriff Eastern equine enzephalitis virus

Beschreibung des Erregers Familie: Togaviridae; Gattung: Alphavirus; Art: Eastern equine encephalitis virus. Plusstrang-RNA-Genom, behüllt, 60-70 nm Durchmesser.

Erkrankungen Vorkommen: von der Ostküste der USA und Kanadas bis zum nördlichen Südamerika.

Vektoren: Stechmücken (Aedes ssp., Coquilletidia ssp., Culex ssp., bei Vögeln Culiseta melanura).

Wirte: Vögel (Virusreservoir), Pferde, Menschen.

Klinik: hohes Fieber, Übelkeit und Erbrechen; bei etwa $6 \%$ der infizierten Kinder und bei 2,5\% der infizierten Erwachsenen entwickelt sich eine Enzephalitis mit Muskelschwäche und -steife, Reflexverminderung, Nackensteifheit, Spasmen, Sensibilitätsstörungen, schlaffen oder spastischen Paresen, auch Persönlichkeitsstörungen sind möglich; Rekonvaleszenz kann Jahre dauern, neurologische Folgeschäden sind möglich, die Letalitätsrate bei Enzephalitis liegt bei $30-75 \%$.

\section{Analytik \\ Kultur: Virusanzucht}

Direktnachweis: Nachweis viraler RNA durch RT-PCR (Polymerase-Kettenreaktion).

Serologie: Nachweis spezifischer Antikörper (IgM, IgG) durch indirekte Immunfluoreszenz (Immunfluoreszenz, indi- rekte), Enzyme-linked Immunosorbent Assay oder Neutralisationstest.

\section{Probenmaterial}

Direktnachweis: Blut und Blutbestandteile, Gewebe oder Liquor. Das Material sollte bis zur Weiterverarbeitung bei +4 bis $+8^{\circ} \mathrm{C}$ aufbewahrt werden.

Serologie: Serum, Plasma oder Liquor. Serumproben für den Nachweis der Antikörper sind bei $+4{ }^{\circ} \mathrm{C}$ bis zu 2 Wochen lang beständig, bei $-20^{\circ} \mathrm{C}$ über Monate und Jahre hinweg. Zur Tiefkühlkonservierung des IgM kann man den Proben $80 \%$ gepuffertes Glyzerin beifügen.

Diagnostische Wertigkeit Die Anamnese ist wichtig. Der Direktnachweis ist nur während der ersten, akuten Krankheitstage möglich. Spezifische Antikörper (IgG, IgM) findet man nach wenigen Tagen im Serum oder Liquor. Ein vierfacher Anstieg des spezifischen Antikörpertiters gilt als eindeutiger Nachweis einer akuten Infektion.

Differenzialdiagnose: Infektionen mit Herpes-Viren, Coxsackie-Viren, oder anderen Arboviren, die das ZNS befallen.

\section{Literatur}

Center for Disease Control and Prevention, Atlanta (2016) Eastern equine encephalitis, 5 Apr. 2016. https://www.cdc.gov/easternequi neencephalitis/. Zugegriffen am 03.02.2017

Center for Food Security and Public Health (2015) Iowa state university. Animal disease information. Equine encephalitides. Latest update Jan 2015. Technical factsheet: eastern, western and venezuelan equine encephalomyelitis. http://www.cfsph.iastate.edu/Factsheets/pdfs/eas ter_wester_venezuelan_equine_encephalomyelitis.pdf. Zugegriffen am 03.02.2017

Robert Koch-Institut, Berlin (2011) Steckbriefe seltener und importierter Infektionskrankheiten. Robert Koch-Institut, Berlin 